\title{
Summer monsoon of 2019: understanding the performance so far and speculating about the rest of the season
}

\author{
Sulochana Gadgil ${ }^{1, *}$, P. A. Francis ${ }^{2}$ and P. N. Vinayachandran ${ }^{1}$ \\ ${ }^{1}$ Centre for Atmospheric and Oceanic Sciences, Indian Institute of Science, Bengaluru 560012 , India \\ ${ }^{2}$ Indian National Centre for Ocean Information Services (Ministry of Earth Sciences, Government of India), Hyderabad 500 090, India
}

\begin{abstract}
The summer monsoon of 2019 began with a massive deficit in the all-India June rainfall of about $33 \%$ of the mean. This led to considerable anxiety since a large deficit in June had occurred last in the summer monsoon of 2014, which had turned out to be a drought. Here, we have attempted to unravel the factors that led to the deficit in June 2019 and also the above-normal rainfall in July. We show that the deficit in June 2019, as that of June 2014, can be attributed to the El Niño. The phase of the other important mode, Equatorial Indian Ocean Oscillation (EQUINOO), has been favourable throughout and led to the recovery of the monsoon in July when the EI Niño weakened. It is expected that EQUINOO will play an important role in determining the rainfall in August and September, and hence the seasonal rainfall in 2019. Analysis of cases like 2003 and 2008, when the positive phase of EQUINOO lasted only during June and July and of 2007, when it lasted throughout the season has given an insight into the role of the sea surface temperature (SST) of the western equatorial Indian Ocean (WEIO) in sustenance of the positive phase of EQUINOO. We find that, unlike in 2003 and 2008, the SST of the WEIO has started increasing in late July, partly due to the mechanism which operated in 2007 and has led to a positive SST anomaly by 10 August, whereas sustained cooling has led to a negative SST anomaly over eastern equatorial Indian Ocean. Since conditions now appear to be favourable for sustenance of a positive phase of EQUINOO, it is expected that the seasonal rainfall will be above normal.
\end{abstract}

Keywords: Deficit rainfall in June, ENSO, EQUINOO, Indian summer monsoon.

EVERY year the monsoon visits our region, but not always with the same gusto. All the facets of the monsoon from the date of onset over Kerala in late May-early June, its progress to cover the entire country in about a month, fluctuations in its intensity during the peak summer monsoon months of July and August, and timing and speed of the retreat vary from year to year. This leads to consider-

*For correspondence. (e-mail: sulugadgil@gmail.com) able interannual variation of the Indian summer monsoon rainfall (ISMR), which is the rainfall received in the country during June-September. Every year, scientists as well as the public are extremely concerned about the monsoon because of the large impact it has on our agriculture and economy ${ }^{1}$. This year, the onset of the monsoon over Kerala was delayed by about a week and the progress was much slower than normal with a long, weak spell until 20 June, which caused a large deficit in the Indian rainfall of June (about $33 \%$ of the mean rainfall) ${ }^{2}$. Since the correlation of ISMR with the date of onset of the monsoon over Kerala is poor ( -0.097 for 1901-2000), we do not expect the delayed onset over Kerala to have any impact on the seasonal rainfall. However, the variation of rainfall in June can contribute substantially to the seasonal rainfall ${ }^{3,4}$, and this variability has been particularly large since 2007 (Figure 1). In 2014, which was the last season with a large deficit in June $(42 \%$ of the mean June rainfall), the season ended with a deficit in ISMR of about $12 \%$, i.e. larger than one standard deviation and hence is considered as a drought.

It is well known that there is a strong link between the interannual variation of ISMR and the El Niño Southern Oscillation (ENSO) over the Pacific, with a high propensity of droughts in the warm phase, viz. El Niño and a high propensity for excess rainfall seasons in the cold phase, viz. La Nina ${ }^{5,6}$. Gadgil and Francis ${ }^{3}$ have shown that the deficit rainfall in June 2014 could be attributed to the El Niño. Even though the El Niño became much weaker in July and August of 2014, there was still some deficit in rainfall, leading to a large deficit in the seasonal rainfall. Since May and June 2019 have been similar to

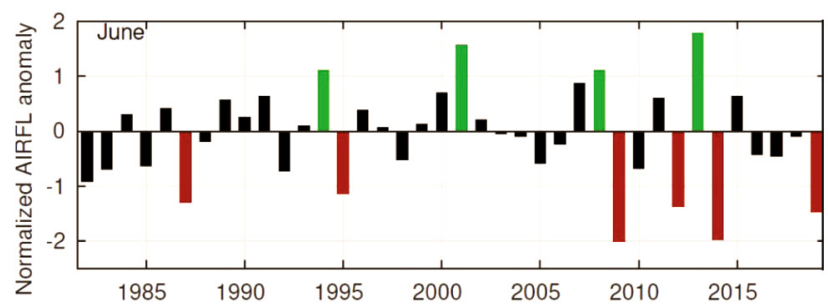

Figure 1. Interannual variation of the anomaly of all-India rainfall in June normalized by the standard deviation during 1982-2019. 


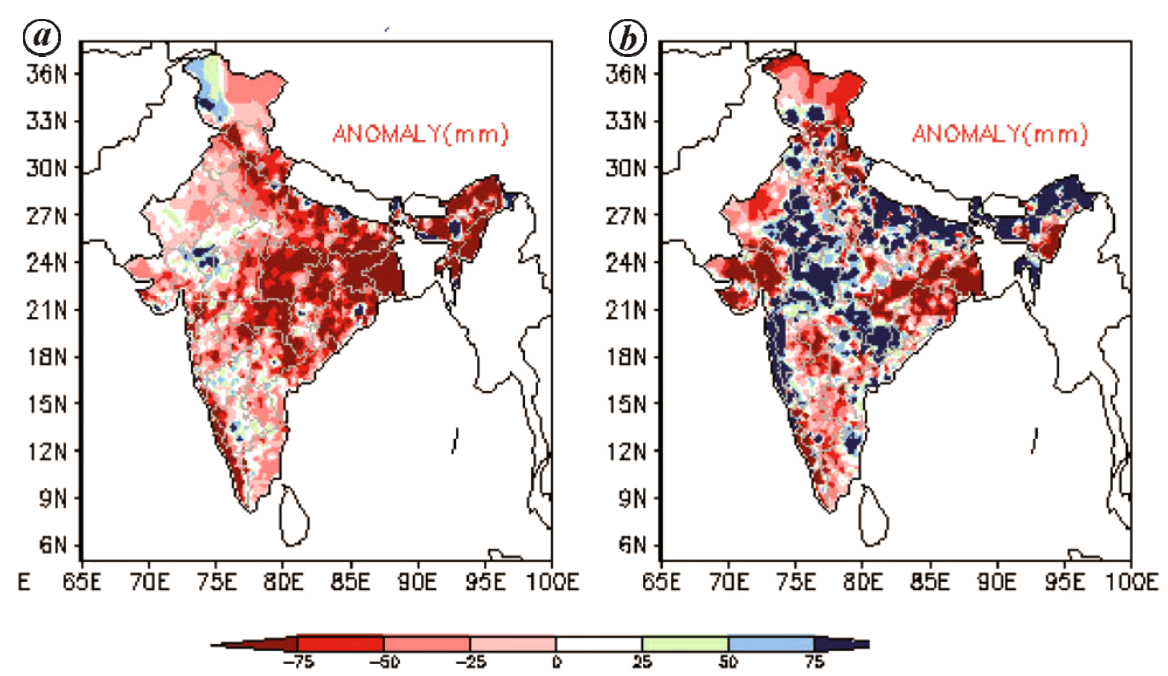

Figure 2. Rainfall anomaly (mm) for June and July 2019 (from http://imdpune.gov.in/Seasons/).

May and June of 2014, with the El Niño of comparable strengths, there was considerable concern at the end of July about the possibility of the monsoon of 2019 also turning out to be a drought. The predictions for the rest of the season of 2019 are generally for weakening of the El Niño ${ }^{7}$, but convection over the equatorial central Pacific has occurred intermittently in July as well. In addition to the link with ENSO, there is a strong link between ISMR and the equatorial Indian Ocean oscillation (EQUINOO) ${ }^{8}$. While the phase of EQUINOO was unfavorable in June 2014 , it was favourable in June 2019. It turns out that the rainfall picked up around 22 June and the July 2019 rainfall has been $4.2 \%$ more than the mean (Figure 2). On the day we submitted this paper, the deficit in June had been made up and the cumulative rainfall was $1.4 \%$ higher than the mean.

In this paper, we first attempt unravelling the factors that played an important role in the large deficit in rainfall of June 2019 and its recovery in July. On the basis of this understanding we speculate about what the future holds in terms of rainfall in the remaining part of the monsoon season and hence in the season as a whole. After discussing the role of the important teleconnections in the interannual variation of ISMR in the next section, we discuss the factors that played a role in the large deficit of June 2019 and the above-normal rainfall in July 2019. Since it is clear that the EQUINOO will play a significant role during the rest of the season as well, what is known about genesis and sustenance of the positive phase of the EQUINOO, is then discussed. Finally, prospects for the rest of the season are considered.

\section{Data}

Daily and monthly mean NOAA outgoing longwave radiation (OLR) data ${ }^{9}$, zonal and meridional wind at $10 \mathrm{~m}$ height from NCEP reanalysis ${ }^{10}$, and NOAA optimal interpolated data of sea surface temperature (SST) data ${ }^{11}$ are extensively used in this study. All the above data have been downloaded from www.cdc.noaa.gov. All-India rainfall data up to 2016 have been downloaded from www.tropmet.res.in and rainfall data for the period 20172019 are based on the operational data provided by India Meteorological Department (www.imd.gov.in). Indices of ENSO have been downloaded from www.cpc.npaa.gov. Sea-level anomaly data downloaded from AVISO webpage and temperature data measured by RAMA moored buoy deployed at $80.5^{\circ} \mathrm{E}$, Equator (www.pmel.noaa.gov) are also used in this study.

\section{Role of ENSO and EQUINOO in the interannual variation of ISMR}

The teleconnections of ISMR with the convection/rainfall over parts of the Indian Ocean and the Asia-Pacific region are clearly seen in Figure $3 a$, which depicts the variation of the correlation of ISMR with the satellitederived OLR (which is a proxy for rainfall in the tropics). The convection/rainfall patterns associated with the ENSO can be gleaned from Figure $3 b$, which depicts the correlation of the ENSO index with OLR. We define the index for ENSO as the normalized (by monthly standard deviation) SST anomaly in the Niño 3.4 region and multiplied with -1 , so that positive values of the ENSO index indicate a cold phase of the ENSO, which is favourable for the monsoon. It should be noted that the highest magnitude of correlation with the ENSO index occurs over the region of the equatorial central Pacific stretching from $150^{\circ} \mathrm{E}$ to $100^{\circ} \mathrm{W}$, with a smaller latitudinal extent east of $120^{\circ} \mathrm{W}$. Enhanced (suppressed) convection over this region is a distinguishing attribute of the warm (cold) phases of the ENSO, i.e. of the El Niño and La Nina. 

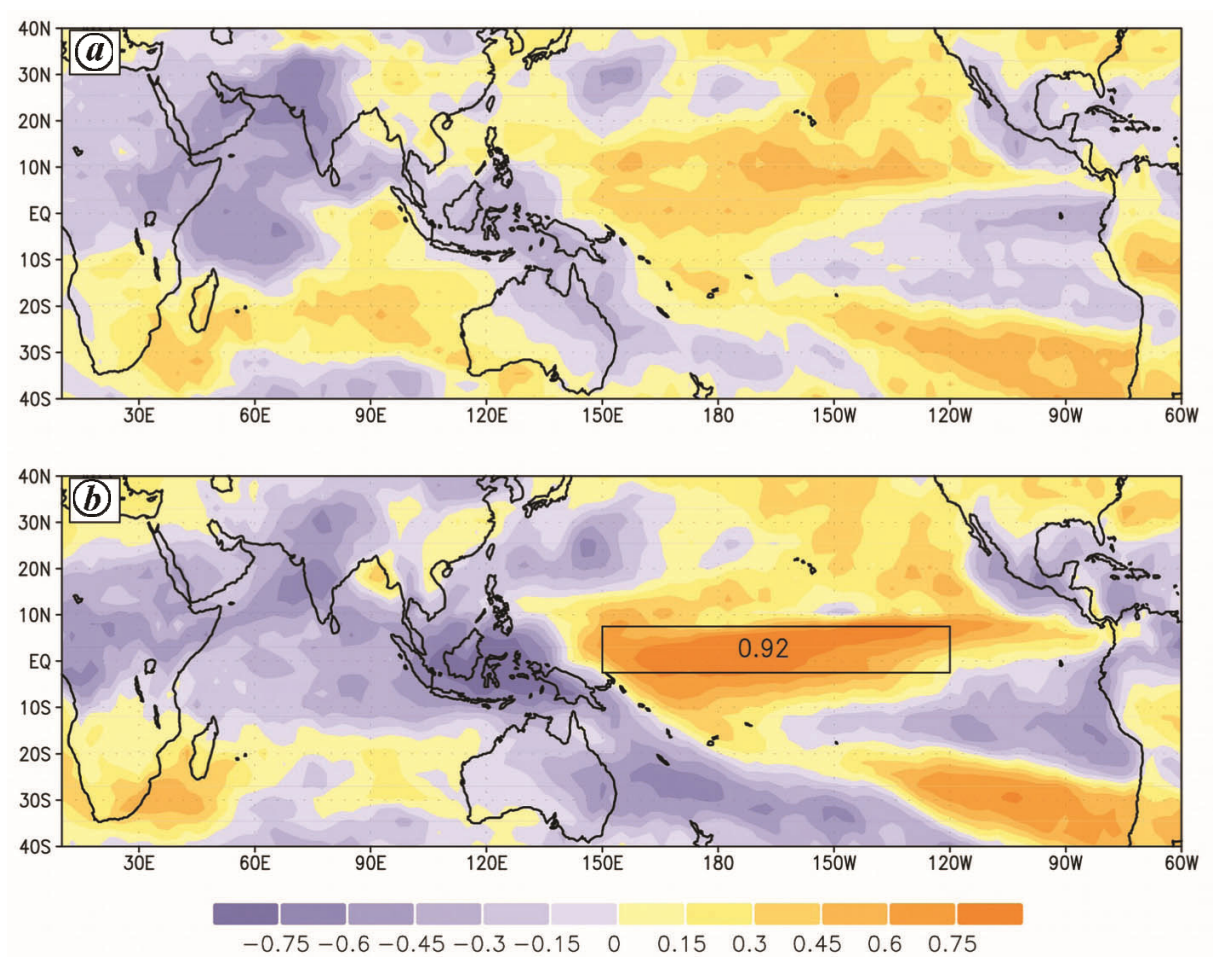

Figure 3. Correlation between June-September mean OLR and (a) ISMR and (b) ENSO index. Correlation between ENSO index and OLR averaged over the equatorial central Pacific $\left(150^{\circ} \mathrm{E}-120^{\circ} \mathrm{W}\right.$ and $\left.2.5^{\circ} \mathrm{S}-7.5^{\circ} \mathrm{N}\right)$ is shown in the box in $(b)$.

Note that convection over the entire equatorial Indian Ocean gets suppressed during the El Niño, but that over the eastern part is more suppressed.

EQUINOO involves an oscillation between a phase in which convection over the west equatorial Indian Ocean (WEIO) is enhanced and that over the east equatorial Indian Ocean (EEIO) is suppressed in the positive phase and with OLR anomalies of the opposite sign over WEIO and EEIO in the negative phase. Associated with the convection anomalies, anomaly of the zonal component of surface winds over the central equatorial Indian Ocean is easterly in the positive phase and westerly in the negative phase of the EQUINOO (Figure $4 a$ ). For analysis of the EQUINOO for a longer period from 1958, we have used an index, EQWIN, based on the zonal component of surface winds over the central equatorial Indian Ocean ${ }^{8}$. The ISMR is well correlated with the ENSO index (0.54) as well as EQWIN (0.44) (ref. 8). At the same time, correlation between the indices of these two modes is very poor in the summer monsoon season (correlation coefficient is $-0.1)$. The extremes of the ISMR are separated in the plane of the indices of these two modes with each drought (excess rainfall season) characterized by an unfavourable (favourable) phase of at least one of the two modes $^{8}$. Severe droughts occur when both the modes are unfavourable. When only one mode is favourable, the sign of the ISMR anomaly depends upon the relative strengths of the two modes. In the summer monsoon of
1997, the two modes were strong and of opposite sign, and the ISMR was close to the mean. The season of 1994 with a strong positive phase of the EQUINOO and a weak El Niño turned out to be an excess rainfall season. It should be noted that these modes also play a role in determining the monthly rainfall during the season. In the season of 1983, June with an El Niño, but a positive phase of the EQUINOO had $15 \%$ deficit rainfall but in August and September, the ENSO became mildly favourable, the EQUINOO highly favourable and rainfall was so much in excess that it turned out be an excess monsoon season. In fact, a composite index derived from these two indices is positive for all excess rainfall years and negative for all droughts, and explains over $53 \%$ of the variance of the interannual variation of the ISMR ${ }^{12}$.

The measurements of OLR are far more robust and reliable than those of the equatorial winds during the summer monsoon, when the mean surface wind over the central equatorial Indian Ocean is close to zero. Hence, for analysis of the EQUINOO in the satellite era, we use an index, EQUINOLR, based on the difference of OLR averaged over the eastern and western equatorial Indian Ocean, so that positive values of EQUINOLR indicate a phase of the EQUINOO which is favourable for monsoon $^{13}$. The OLR of the EEIO is negatively correlated with that of the WEIO. Thus enhanced (suppressed) convection over the WEIO is associated with suppressed (enhanced) convection over the EEIO. Figure $4 c$ shows 


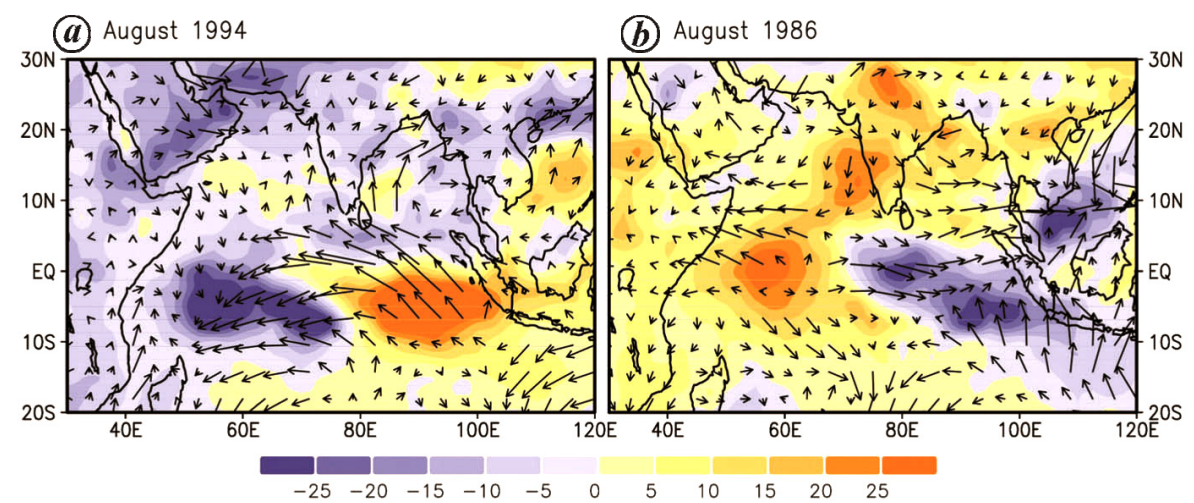

(c) Correlation between EQUINOLR \& OLR

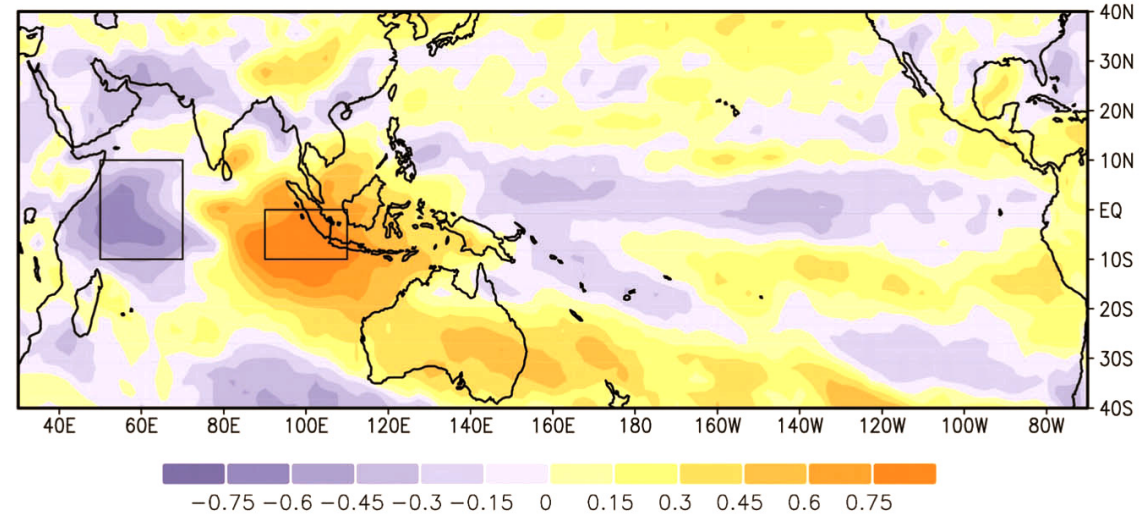

Figure 4. OLR and surface wind anomaly patterns for (a) August 1994 and (b) August 1986. (c) Correlation between June-September OLR and EQUINOLR.

the correlation of the EQUINOLR with OLR. It can be seen from Figures $2 b$ and $3 b$ that unfavourable phase of the ENSO for the monsoon, i.e. enhanced convection/rainfall over the central equatorial Pacific Ocean is associated with suppression of convection over the EEIO, i.e. favourable phase for the EQUINOO.

It is well known that the atmospheric component of the ENSO, i.e. the Southern Oscillation is strongly coupled with the oceanic components, viz. El Niño and La Nina, with the correlation of indices of the two being higher than 0.85 . EQUINOO is considered to be the atmospheric component of the coupled Indian Ocean mode ${ }^{14,15}$, and oceanic conditions and interactions with the ocean will play an important role in determining the patterns of convection/precipitation associated with different phases. However, the coupling between atmospheric and oceanic components is weaker than for the ENSO, and while the index of the EQUINOO is well correlated with the ISMR, the index of the oceanic component, DMI, which is the difference between the SST anomalies of the WEIO and EEIO, is poorly correlated with the ISMR ${ }^{8}$. We consider that the link between monsoon rainfall and the ENSO is primarily via the connection with the atmospheric convection anomalies which characterize the ENSO, just as the link with the EQUINOO is primarily via the connec- tion with the atmospheric convection anomalies. Hence our analysis focuses on the atmospheric convection patterns.

\section{Rainfall in June and July 2019}

\section{June rainfall}

Consider first the relationship of the variation of June rainfall with convection over different parts of the Indian and Pacific Oceans, and the nature of the convection patterns associated with the ENSO and EQUINOLR in June (Figure 5). Over the tropical Pacific, the largest correlation coefficient of June rainfall $(0.56)$ is with the OLR over the northwest tropical Pacific (NWTP: $120^{\circ}-150^{\circ} \mathrm{E}$, $20^{\circ}-30^{\circ} \mathrm{N}$ ) region (Figure 5). Over the Indian ocean, the highest correlation coefficient $(0.36)$ is with the OLR over the southeast equatorial Indian Ocean (SEEIO: $85^{\circ}$ $\left.105^{\circ} \mathrm{E}, 5^{\circ}-15^{\circ} \mathrm{S}\right)$. From the relationships of the June rainfall with convection over these two regions (Figure 6), it can be seen that all the years with large excess in June rainfall (with normalized rainfall anomaly greater than 1) have favourable convection anomaly over at least one of the two regions, and all the years with large deficits (with normalized rainfall anomaly less than -1 ) have unfavourable 


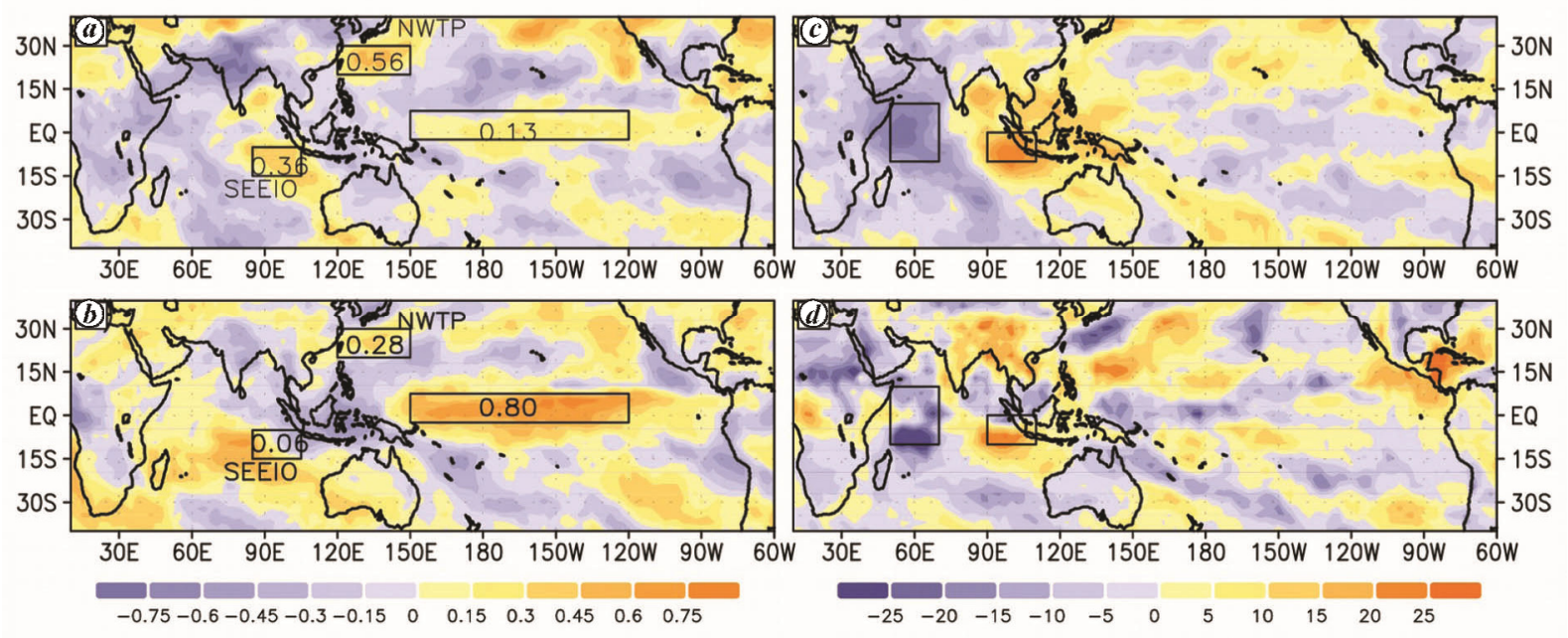

Figure 5. Correlation between June OLR and (a) June all-India rainfall, (b) June ENSO index and (c) June EQUINOLR. (Color bar shown below (b); OLR anomaly for June 2019). Values of correlation coefficient between June all-India rainfall (ENSO index) and OLR averaged over northwest tropical Pacific (NWTP), central Pacific $\left(150^{\circ} \mathrm{E}-120^{\circ} \mathrm{W}, 2.5^{\circ} \mathrm{S}-7.5^{\circ} \mathrm{N}\right)$ and southeast equatorial Indian Ocean (SEEIO) are given in the boxes shown over the respective region in $(\boldsymbol{b})$.
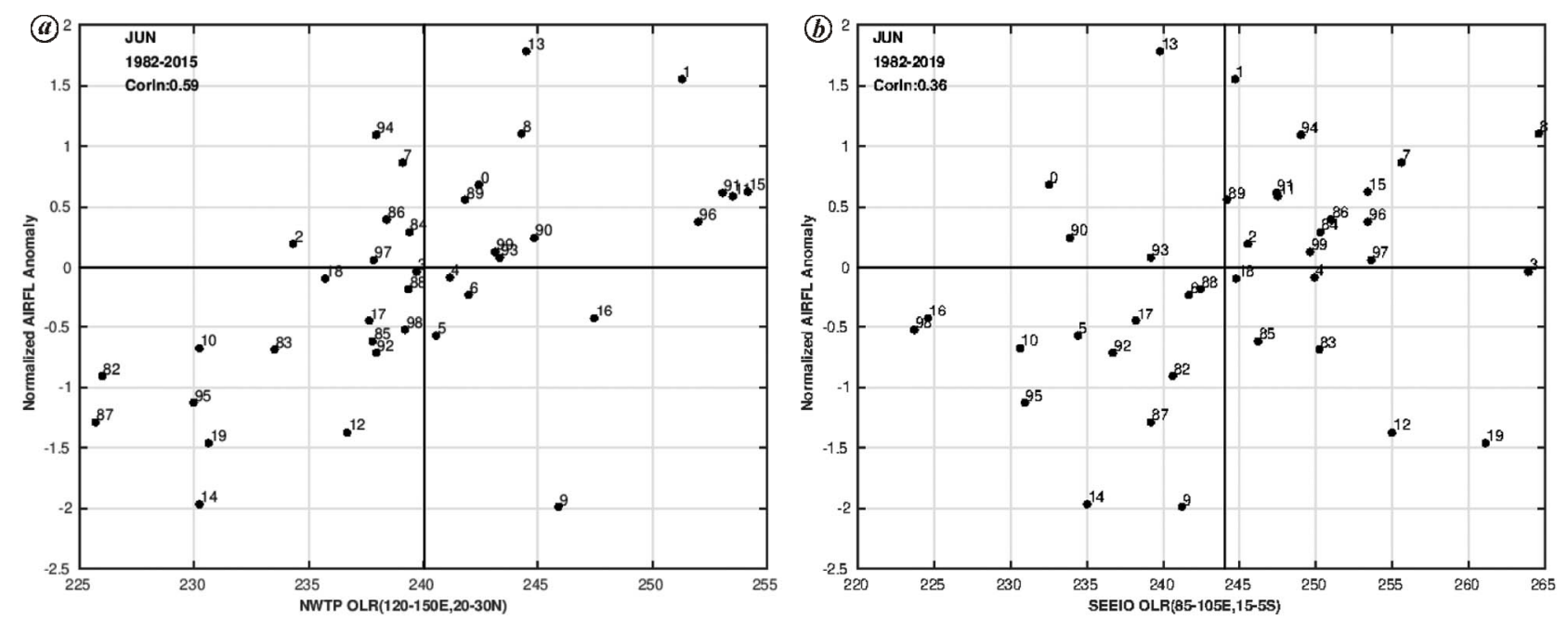

Figure 6. Variation of all-India June rainfall anomaly with OLR of $(\boldsymbol{a})$ NWTP $\left(120^{\circ}-150^{\circ} \mathrm{E}, 20^{\circ}-30^{\circ} \mathrm{N}\right)$ and $(\boldsymbol{b})$ SEEIO $\left(85^{\circ}-105^{\circ} \mathrm{E}\right.$, $\left.5^{\circ}-150^{\circ} \mathrm{S}\right)$.

convection anomaly over at least one of the two regions. In June 2019 which is of interest here, while the OLR anomaly over the NWTP is unfavourable, convection over the SEEIO is suppressed (Figure 5) which would mitigate to some extent the adverse impact of the NWTP anomaly. However, in the case of June 2014, which had a much larger rainfall deficit, the OLR anomaly was unfavourable over both the regions.

The rainfall in June is not highly correlated with the ENSO index (correlation coefficient: 0.22 ), but we find that four out of five years with large deficits are associated with negative values of the index, i.e. El Niños of varying strength. The poor correlation arises from there being hardly any relationship between the other years and the ENSO index. However, the pattern correlation of the
OLR of the West Pacific $\left(120^{\circ}-150^{\circ} \mathrm{E}, 10^{\circ} \mathrm{S}-30^{\circ} \mathrm{N}\right)$ with the ENSO index and with the Indian rainfall in June is 0.7 , suggesting a strong link between June rainfall and the ENSO via the convection over the West Pacific. The correlation with the EQUINOO is also not high (correlation coefficient is 0.19 ), but there is a high propensity of normal or excess rainfall in June, if the EQUINOLR is positive.

Convection over NWTP, SEEIO and relation with ENSO and EQUINOO: It is seen that in the convection pattern associated with the ENSO (Figure 5), the OLR anomaly over the NWTP is of the same sign as that over the equatorial central Pacific. Thus it is expected that during the El Niño years, convection over the NWTP will be 
enhanced. Gadgil and Francis ${ }^{3}$ have shown that, although the correlation of the NWTP OLR with the ENSO index is not large $(0.28$, Figure 5), if cases in which there is convection over the equatorial central Pacific (OLR < $240 \mathrm{Wm}^{-2}$ ) are considered, convection occurs over the NWTP in seven out of nine years. Thus, there is a high propensity of convection over the NWTP in the El Niño years.

Gadgil and Francis ${ }^{3}$ have also shown that intensification of convection over the NWTP occurs with the southward migration of the subtropical jet. Such a southward migration also occurred in June 2019 (figure not shown). These observations lend support to the results of a study of a barotropic model by Shaman and Tziper$\operatorname{man}^{16}$ that the impact of enhanced convection over the equatorial central Pacific associated with the El Niño, is an increase in the vorticity anomalies within the North African-Asian jet. They showed that westward-propagating anomalies in both the tropics and middle latitudes produced the anomaly response within this jet and suggested that the teleconnection linking the ENSO and monsoons is mediated by the response of this jet to westward-propagating Rossby waves ${ }^{16}$.

Using high-resolution Meteorological Research Institute model, which shows high skill in simulating important features of Asian summer monsoon and its variability, Sajani et $a l .^{4}$ showed that, as observed, there is an inverse relationship between the simulated NWTP rainfall and the simulated rainfall over the Indian region in June. They also found that in years with large rainfall excess/deficit, the strong link between June rainfall and the NWTP rainfall existed through differences in Rossby wave phase steered in the subtropical jet.

It is thus clear that as in 2014, the El Niño had an adverse impact on the June rainfall over the Indian region in 2019 as well. We note that the OLR anomaly pattern over the equatorial Indian Ocean for June 2019 (Figure 5), clearly showed that the phase of the EQUINOO was favourable. The OLR anomaly of the SEEIO was also favourable, which is not surprising since the OLR over the SEEIO is highly correlated (correlation coefficient 0.87) with that over the EEIO, which is the eastern pole of the EQUINOO. Hence the suppression of convection over the SEEIO will have mitigated to some extent the adverse impact of the El Niño via the intensification of convection over the NWTP. We may, therefore, conclude that the large deficit in the June rainfall of 2019 can be attributed to the El Niño.

\section{July rainfall}

The July rainfall is well correlated with the ENSO index (correlation coefficient 0.39) as well as EQWIN (correlation coefficient 0.41). Comparison of July 1997, a case in which the two modes had opposite impacts on monsoon rainfall, with the ENSO stronger than the EQUINOO (indices -2.69 and 1.1 respectively) and rainfall a little below normal, with July 1987 with both the ENSO and EQUINOLR unfavourable (indices -2.41 and -1.12 respectively) and rainfall deficit of over $27 \%$, suggests the critical role played by the EQUINOO. In 2019, the strength of the El Niño has reduced from June (ENSO in$\operatorname{dex}=-0.86$ ) to July (ENSO index -0.51). Meanwhile strength of the EQUINOLR increased from 1.13 to 1.36 . It is interesting that in July 2014 with comparable values of the ENSO index but unfavourable EQUINOO (index -1.53 ) rainfall was $10 \%$ deficit, whereas in July 2019 rainfall was $4.2 \%$ in excess, suggesting the role of favourable EQUINOO in 2019 in mitigating the impact of the El Niño. Thus we suggest that the EQUINOO played a role in the above-normal rainfall in July.

With this understanding of the anomalies of the Indian rainfall in June and July 2019, we can assess the prospects for August-September. It has been predicted that the El Niño would weaken with time ${ }^{7}$. Thus, how the phase of the EQUINOO will evolve, i.e. whether the intensified convection over the WEIO will be sustained in August and September, will play a critical role in the rainfall of these two months. While the ENSO predictions are available for several months ahead, predicting the evolution of the EQUINOO still remains a challenge. We consider next the factors that play an important role in the evolution of the EQUINOO, and particularly, the positive phase of the EQUINOO which is favourable for monsoon.

\section{Genesis and sustenance of the positive phase of EQUINOO}

We note that positive IOD events (i.e. with the normalized difference between the SST anomalies of the WEIO and EEIO, DMI, exceeding 1) such as 1994 and 1997 are characterized by a positive phase of the EQUINOO (e.g. 1994 in Figure $4 a$ ). However, the converse is not true as is clear from the case of the summer monsoon season of 2007, in which a sustained positive phase of the EQUINOO occurred which was not associated with a positive dipole event. In fact, genesis of a positive phase of the EQUINOO is the first step in the triggering of positive IOD events. However, such genesis does not always lead to a sustained positive phase throughout the summer monsoon season. In 2003 and 2008, positive phase of the EQUINOO occurred only during June and July. We can get an insight into the evolution of the positive phase of the EQUINOO by considering all these cases.

An important factor determining whether deep convection (generally indicated by monthly OLR $<240 \mathrm{Wm}^{-2}$ ) occurs over the tropical oceans is SST. It is well known that for deep convection to occur over the tropical oceans, 
SST has to be above a threshold of about $27.5^{\circ} \mathrm{C}$ (refs 17 , 18). This is clear from Figure 7, which shows that for SST below this threshold for the WEIO and EEIO, the frequency of the monthly OLR being less than $240 \mathrm{Wm}^{-2}$ is less than $10 \%$.

Figure $8 a$ shows the annual cycle of climatological OLR and SST averaged over the WEIO and EEIO. The annual cycle of the climatological zonal component of surface winds over the central equatorial Indian Ocean is also shown in the figure. In addition, variation of monthly OLR and SST of the WEIO and EEIO, and zonal component of surface winds over the equatorial Indian Ocean for 1997 in which a positive IOD event occurred, 2007 in which positive EQUINOO was sustained during the entire summer monsoon and 2003 in which positive EQUINOO occurred only during June and July are shown in the figure. As a measure of convection over a region on a daily scale, we use a convective index $(\mathrm{CI})^{19}$, which is the sum of $200 \mathrm{Wm}^{-2}$-OLR for all the grids in the region for which this quantity is positive, i.e. can be considered to have convection. Figure $8 b$ shows the variation of CI over the WEIO and EEIO for these years.

It is seen that climatologically SST of the EEIO is high in April and May and decreases thereafter until September, when it begins to rise again. However, it is above the SST threshold throughout the year and convection also occurs throughout the year, though the intensity of convection is relatively low during the summer monsoon season (Figure $8 a$ ). The climatological SST of the WEIO is even higher in April and May, decreases thereafter to reach a minimum in August which is a little below the threshold and then increases again, being slightly less than the SST of EEIO from June onwards. Some convection occurs over the WEIO only during June to August
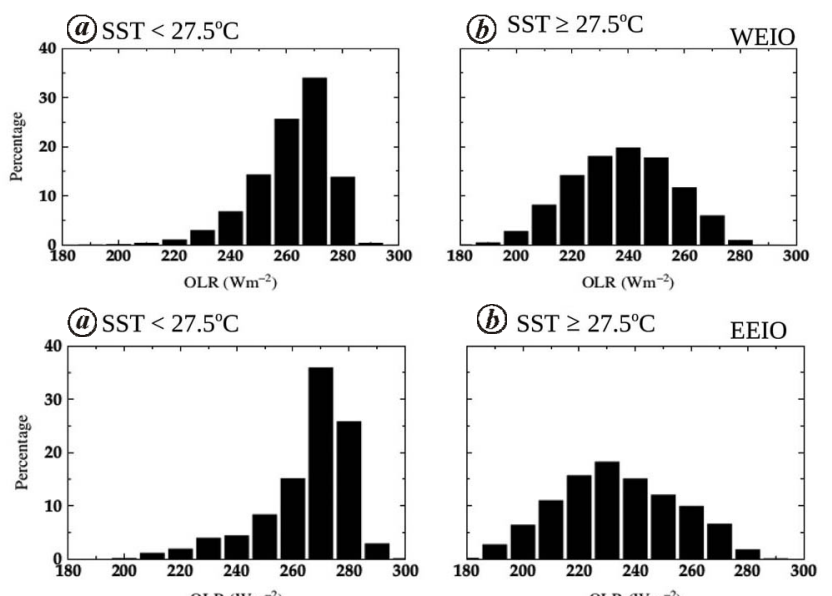

Figure 7. Frequency distribution of the OLR of western equatorial Indian Ocean (WEIO) (top) and east equatorial Indian Ocean (EEIO) (bottom) for the months of June, July, August and September in the period 1982-2018, when sea surface temperature (SST) was $<27.5^{\circ} \mathrm{C}$ (left) and $\geq 27.5^{\circ} \mathrm{C}$ (right). when the mean OLR becomes comparable to that over the EEIO. Weak eastward gradients in convection and SST across the equatorial Indian Ocean in the summer monsoon lead to weak westerlies, with mean zonal wind over the central equatorial Indian Ocean close to zero.

It should be noted that even when the monthly OLR is lower over the EEIO, convection occurs on some days over the WEIO, provided SST is above the threshold; the lower OLR of the EEIO arises from higher propensity of convection over the EEIO. OLR over the WEIO is negatively correlated with that of the EEIO on daily, monthly and seasonal scales because there is competition between convection over these regions, with the convection being enhanced (suppressed) over the WEIO (EEIO), when it is suppressed (enhanced) over the EEIO (WEIO). Hence, suppression of convection over the EEIO can lead to enhancement of convection over the WEIO. Associated with this, equatorial wind anomalies become easterlies, enhancing the convergence over the WEIO. This atmospheric feedback can further enhance the convection over the WEIO and keep the EEIO convection suppressed, leading to the initiation of a positive EQUINOO with easterly anomalies over the central equatorial Ocean.

In fact, the first step in the triggering of a positive IOD is the evolution of a positive EQUINOO. This involves suppression of convection over the EEIO, enhancement of convection over the WEIO and associated changes in the circulation pattern. Francis et al. ${ }^{19}$ have shown that all the positive IOD events during the period 1982-2004 are preceded by the occurrence of a severe cyclone over the Bay of Bengal during April/May. They showed that the strong convection over the Bay associated with severe cyclones suppresses convection over the EEIO, which leads to enhancement of convection over the WEIO. Further, intense meridional pressure gradient in the eastern part of the Indian Ocean can intensify the upwelling favourable alongshore winds off the west coast of Sumatra, leading to cooling of the EEIO and weakening of the eastward SST gradient. Weak eastward gradients in convection and SST across the equatorial Indian Ocean in the summer monsoon lead to weaker westerlies.

The cyclones are relatively short-lived and suppression of convection over the EEIO associated with these cyclones does not last for more than a few days. However, with the establishment of convection over the WEIO and associated positive atmospheric feedback, convection over the EEIO can remain suppressed for several weeks over the EEIO leading to a positive phase of the EQUINOO, so that conditions favourable for the development of positive IOD continue for a longer period.

For sustenance of the positive EQUINOO phase, it is necessary that convection is sustained over the WEIO. The mixed layer temperature of the WEIO is primarily determined by the air-sea fluxes ${ }^{20,21}$. Hence, prolonged convection and enhanced surface winds over the WEIO can lead to a decrease in SST. As a result, if SST 

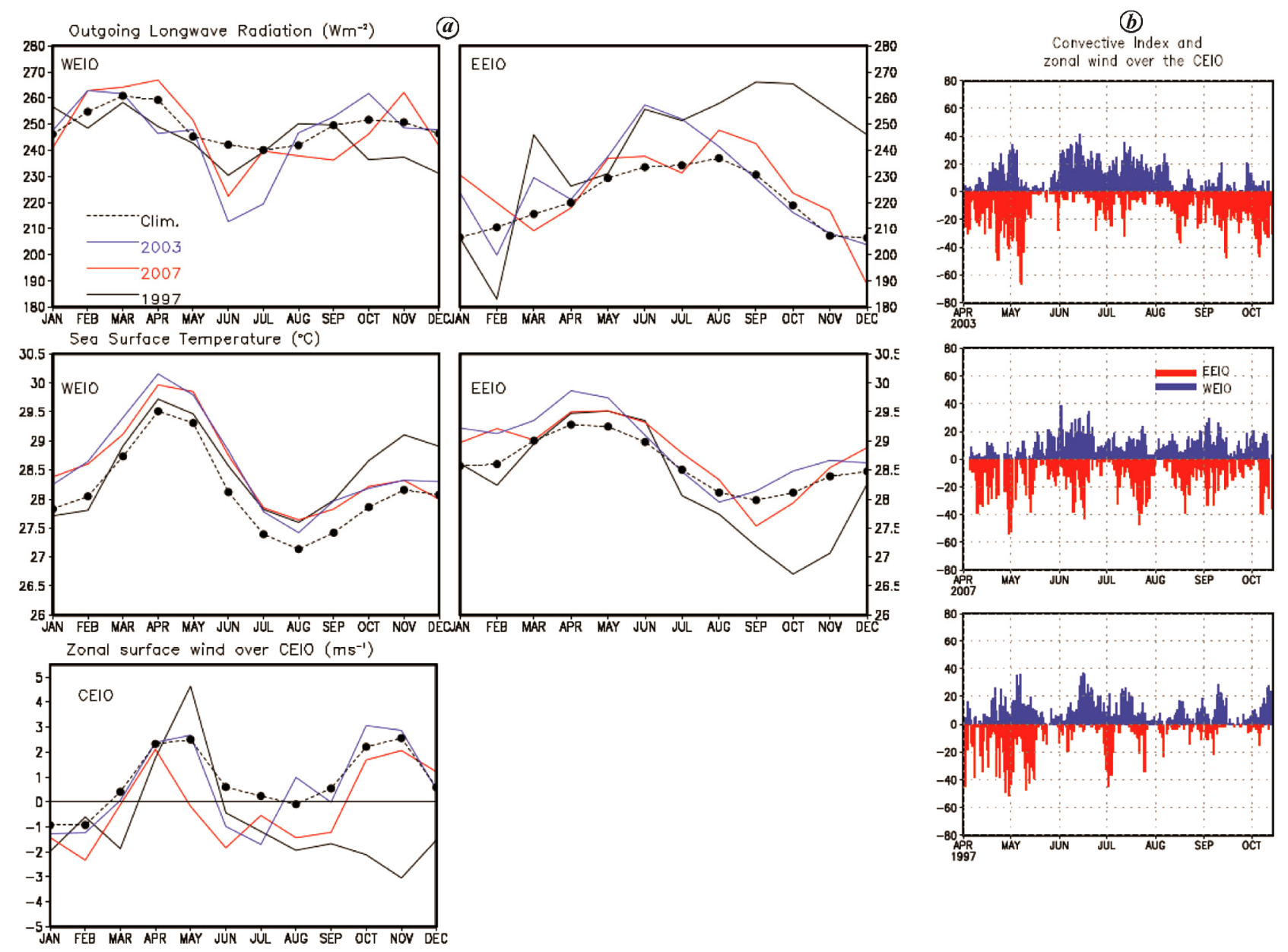

Figure 8. $\boldsymbol{a}$, Time series of monthly mean OLR and OLR for 2003, 2007 and 1997 (top), and SST (middle) averaged over the WEIO (left panels) and the EEIO (right panels). Time series of monthly mean surface zonal wind averaged over the $\mathrm{CEIO}\left(60^{\circ}-90^{\circ} \mathrm{E}, 2.5^{\circ} \mathrm{S}-2.5^{\circ} \mathrm{N}\right)$ (bottom). b, Variation of daily convective index during April-October for the WEIO and EEIO (multiplied by -1) for 2003 (top), 2007 (middle) and 1997 (bottom).

decreases below this threshold and SST of the EEIO remains higher than the threshold for deep convection, the convection can get switched from the WEIO to EEIO. In 2003, the SST in the WEIO decreased below the threshold of $27.5^{\circ} \mathrm{C}$ and the positive phase of the EQUINOO was terminated by early August (Figure $8 b$ ).

Climatologically, SST of the EEIO is always above the threshold whereas that of the WEIO is slightly below this threshold in August. In fact, when the EEIO cools in a positive IOD event, SST drops below this threshold and then convection cannot occur on the EEIO until it warms again and crosses the threshold. With the development of a strong positive EQUINOO, easterly wind bursts over the central equatorial Indian Ocean can trigger upwelling Kelvin waves, which propagate eastward and downwelling Rossby waves that propagate westward ${ }^{19,20}$. The eastward-propagating, upwelling Kevin waves upon reaching the EEIO lift the isothermal layers and set favourable conditions for efficient cooling due to coastal upwelling. At the same time, westward-propagating, downwelling Rossby waves deepen the isothermal layers in the WEIO, which can decrease the efficiency of seasonal cooling. If this mechanism continues for a sufficient period (as in 1997) and SST in the EEIO drops below the threshold for deep convection, it can lead to a positive $\mathrm{IOD}^{19}$.

There was prolonged convection over the WEIO in 2007 from mid-May to the end of September, despite there being no strong positive IOD event. It may be noted that even though there was intense convection, SST anomalies of the WEIO remained positive and SST remained higher than $27.5^{\circ} \mathrm{C}$ throughout the season. This was associated with deeper than normal isothermal layers in the WEIO. Effy et al. (pers. commun., 2019) have shown that higher mixed layer temperature of the WEIO during June/July 2007 was maintained as a result of lessefficient vertical processes. They showed that this was due to the deepening of isothermal layers with the arrival of two downwelling Rossby waves from the EEIO, one as a direct response of easterly wind burst and 
(a) May 2019

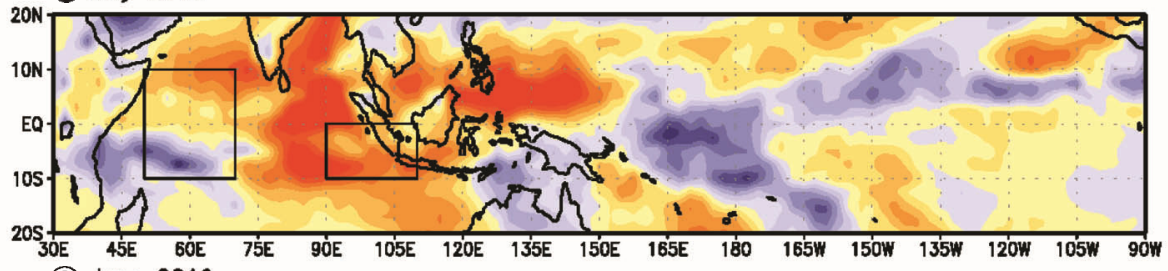

(b) June 2019

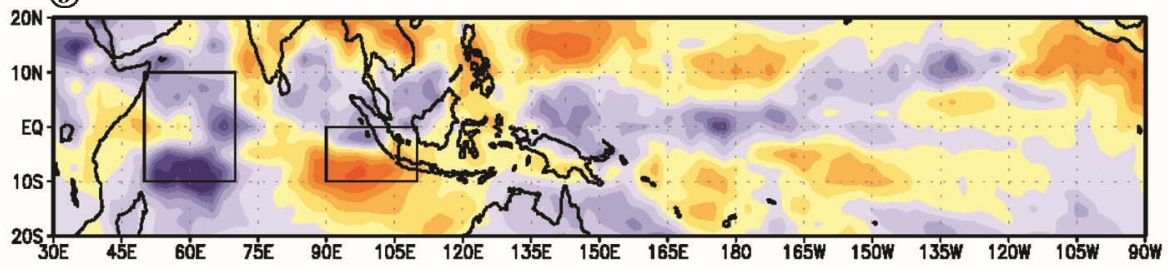

(C) July 2019

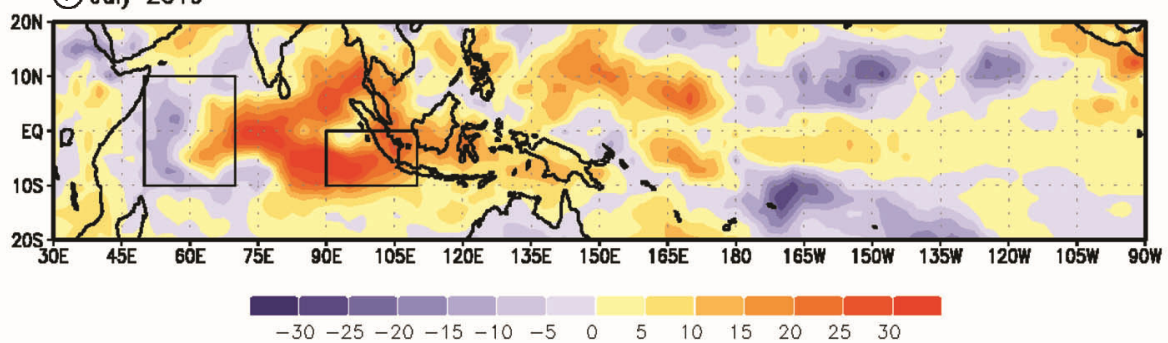

Figure 9. OLR anomalies for (a) May, (b) June and (c) July 2019.
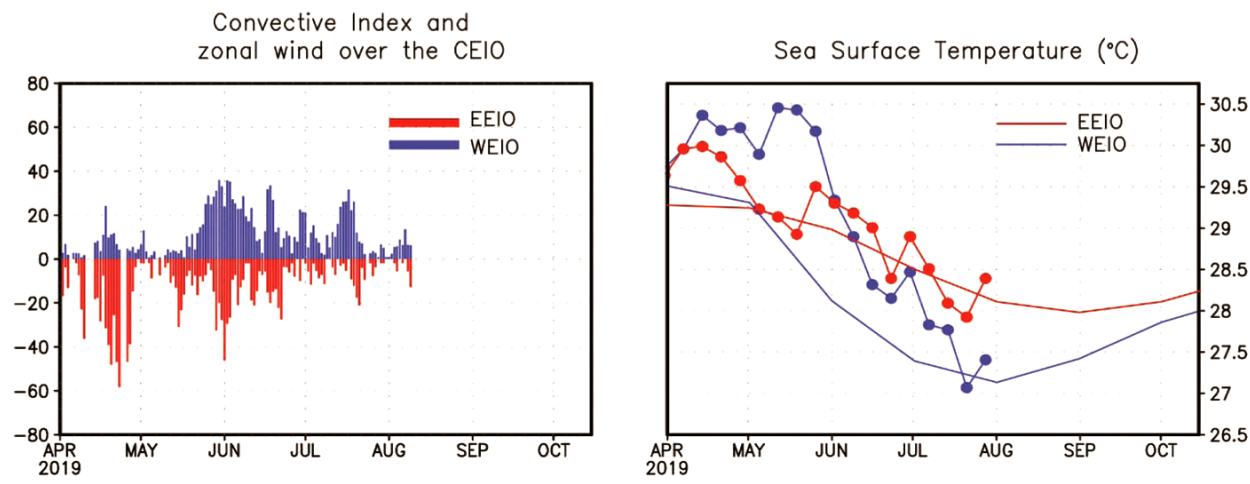

Figure 10. (Left) Variation of convective index for the WEIO and EEIO (multiplied by -1) in 2019. (Right) Variation of SST averaged over the WEIO and EEIO. Climatology of SST is shown as continuous curve.

another reflected from the eastern boundary when the downwelling Kelvin wave (triggered by the westerly wind burst in the first half of April) encountered the eastern boundary.

\section{Season of 2019}

It is clear that the deficit in June rainfall can be attributed to the El Niño. From May onwards through June and July, the EQUINOLR has been favourable and in July the ENSO became weaker (Figure 9), hence the positive rainfall anomaly could be attributed to the EQUINOO. It has been predicted that the El Niño would weaken with time ${ }^{7}$. Thus, how the phase of the EQUINOO will evolve, i.e. whether the intensified convection over the WEIO will be sustained in August and September, will play a critical role in the rainfall of these two months. We will now make an educated guess about whether convection over the WEIO, i.e. the positive phase of the EQUINOO will be sustained in August and September on the basis of the understanding of all the cases considered.

The convection over the EEIO first got suppressed with the very severe cyclone 'Fani', over the Bay in early May, and remained subdued until the last week of June 

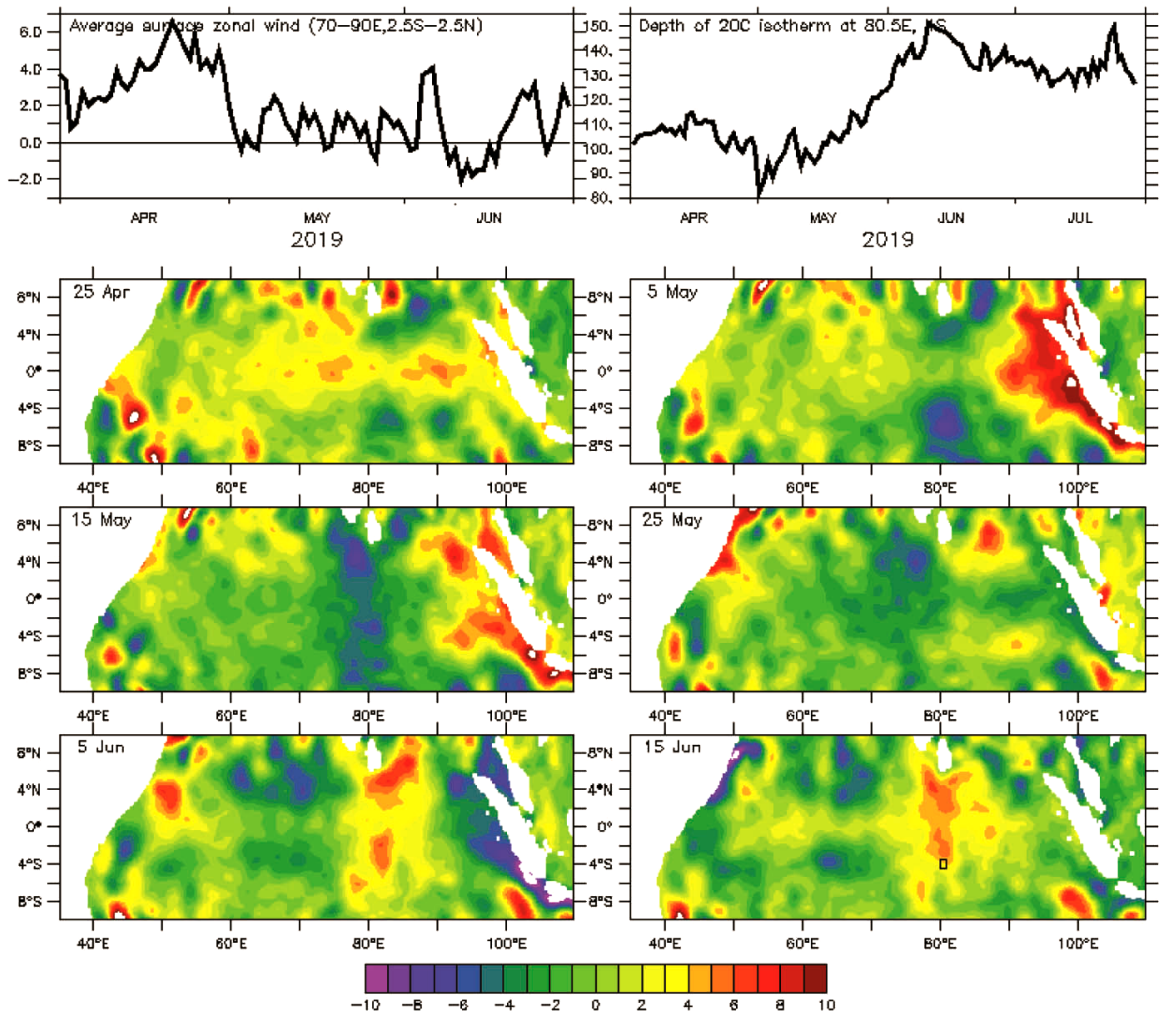

Figure 11. (Top left) Average zonal wind over $70^{\circ}-90^{\circ} \mathrm{E}, 2.5^{\circ} \mathrm{S}-2.5^{\circ} \mathrm{N}$. (Top right) Time series of depth of $20^{\circ} \mathrm{C}$ isotherm at $80.5^{\circ} \mathrm{E}, 4^{\circ} \mathrm{S}$. (Lower panels) $20-70$-days band pass filtered sea-level anomaly maps on selected days.

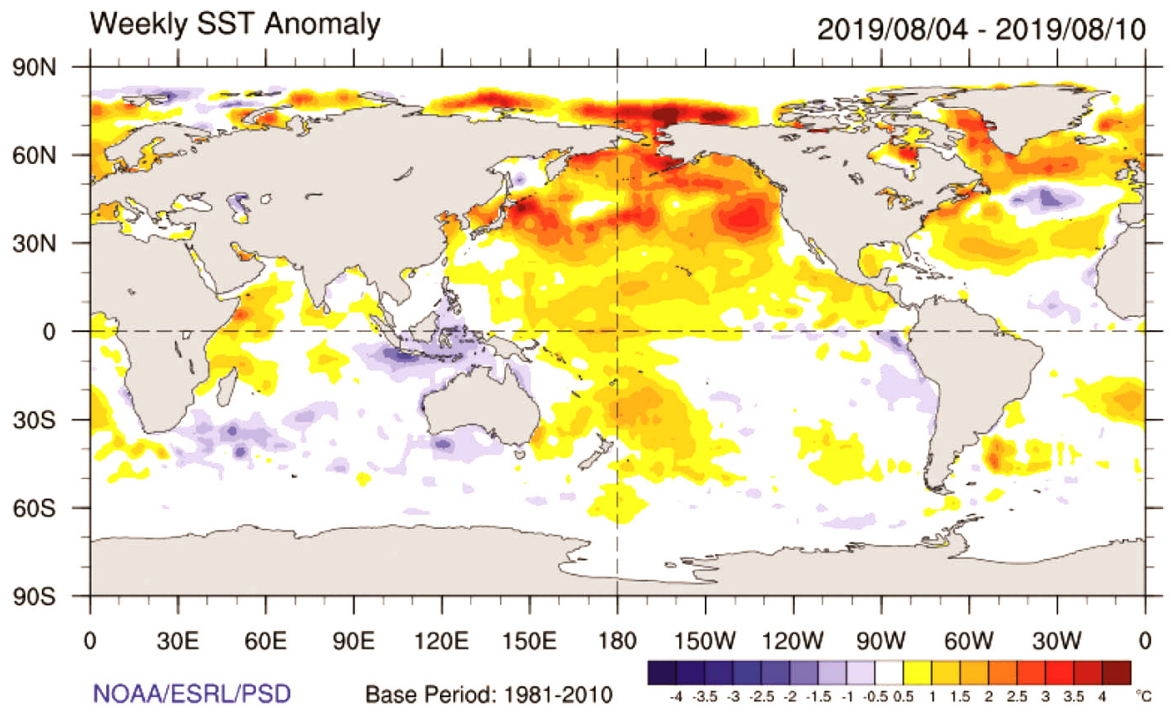

Figure 12. Map of SST anomaly during 4-10 August 2019. (Source: https://www.esrl.noaa.gov/psd/map/clim/sst.shtml)

and was even further suppressed in July, while convection over the WEIO increased in June and was sustained until the end of July (Figure 10). In addition to the active convection over the WEIO, the El Niño also must have contributed towards suppression of convection over the EEIO. From June to mid-July, SST of the EEIO was slightly higher than that of the WEIO, but both were above the threshold; so clearly dynamical factors played a role in suppressing the convection of OLR of the EEIO.

During June-July when the convection was sustained over the WEIO, SST decreased rapidly (Figure 10). However, this decrease was arrested towards the end of July 
and SST began to increase again. Two factors appear to have contributed to this recovery of SST of the WEIO. As in 2007, the oceanic response to the westerly wind burst in the CEIO during the third week of April was an eastward-propagating downwelling Kelvin wave and reflected downwelling Rossby wave, which propagated westward (Figure 11). In fact, deepening of the thermocline associated with the arrival of downwelling Rossby wave can be seen in the moored buoy observation at $80.5^{\circ} \mathrm{E}, 4^{\circ} \mathrm{S}$ in the first two weeks of June. It is expected that this Rossby wave would have arrived at the WEIO by the end of July and deepened the isothermal layers in the region. There was a short spell towards the end of July when convection over the EEIO revived a little, but from the last week of July convection over the WEIO and EEIO remained suppressed. Interestingly, with the suppression of convection over the entire equatorial Indian Ocean, SST of both the EEIO and WEIO increased in the first week of August. The spatial pattern of SST in the first week of August is characterized with positive anomalies in the WEIO and negative anomalies in the EEIO, typical of a positive IOD (Figure 12).

With this favourable east-west gradient in SST in the equatorial Indian Ocean, it is possible that the convection over the western parts of the equatorial Indian Ocean will be enhanced and that over the EEIO will remain suppressed in the coming weeks. In addition, with the positive SST anomalies in the central Pacific, there has been intermittent convection near the date-line. This also suppresses the convection over the EEIO dynamically. Hence, unlike in the aborted EQUINOO cases of 2003 and 2008, when there was no significant convection over the central Pacific, it is expected that the EQUINOO development may strengthen in the second part of the monsoon season in 2019. This will be a favourable situation and could lead to above-normal rainfall for the season as a whole.

1. Gadgil, Sulochana and Gadgil, Siddhartha, The Indian monsoon, GDP and agriculture. Econ. Polit. Wkly., 2006, XLI, 4887-4895.

2. http://www.imd.gov.in (accessed on 14 August 2019).

3. Gadgil, Sulochana and Francis, P. A., El Niño and the Indian monsoon in June. Curr. Sci., 2016, 110(6), 1010-1022.

4. Sajani, S., Gadgil, Sulochana, Rajendran, K., Varghese, S. J. and Kitoh, A., Monsoon rainfall over India in June and link with northwest tropical Pacific. Theor. Appl. Climatol., 2018, https:// doi.org/10.1007/s00704-018-2440-6

5. Sikka, D. R., Some aspects of the large scale fluctuations of summer monsoon rainfall over India in relation to fluctuations in the planetary and regional scale circulation parameters. Proc. Indian Acad. Sci. (Earth Planet. Sci.), 1980, 89, 179-195.
6. Gadgil, Sulochana, Rajeevan, M. and Francis, P. A., Monsoon variability: links to major oscillations over the equatorial Pacific and Indian oceans. Curr. Sci., 2007, 93(2), 182-194, and references therein.

7. ENSO: Recent evolution, current status and predictions. Update prepared by Climate Prediction Center/NCEP, 29 July 2019; https://www.cpc.ncep.noaa.gov

8. Gadgil, Sulochana, Vinayachandran, P. N. and Francis, P. A., Extremes of the Indian summer monsoon rainfall, ENSO and equatorial Indian ocean oscillation. Geophys. Res. Lett., 2004, 31, L12213.

9. Liebmann, B. and Smith, C. A., Description of a complete outgoing longwave radiation dataset. Bull. Am. Meteorol. Soc., 1996, 77, 1275-1277.

10. Kalnay, E. et al., The NCEP/NCAR 40-y reanalysis project. Bull. Am. Meteorol. Soc., 1996, 2, 437-471.

11. Reynolds, R. W. and Smith, T. M., A high resolution global sea surface temperature climatology. J. Climate, 1995, 8, 1571-1583.

12. Sajani, S., Gadgil, S., Francis, P. A. and Rajeevan, M., Prediction of Indian rainfall during the summer monsoon season on the basis of links with equatorial Pacific and Indian Ocean climate indices. Environ. Res. Lett., 2015, 10, 094004, doi:10.1088/17489326/10/9/094004

13. Francis, P. A. and Gadgil, Sulochana, A note on new indices for the equatorial Indian Ocean oscillation. J. Earth Syst. Sci., 2013, 122(4), 1005-1011.

14. Saji, N. H., Goswami, B. N., Vinayachandran, P. N. and Yamagata, T., A dipole mode in the tropical Indian Ocean. Nature, 1999, 401, $360-363$.

15. Vinayachandran, P. N., Jahfer, S. and Nanjundiah, R. S., Impact of river runoff into the ocean on Indian summer monsoon. Environ. Res. Lett., 2015, 10, 054008.

16. Shaman, J. and Tziperman, E., Summertime ENSO-North African-Asian jet teleconnection and implications for the Indian monsoons. Geophys. Res. Lett., 2007, 34, L11702; doi:10.1029/ 2006GL029143.

17. Gadgil, Sulochana, Joseph, P. V. and Joshi, N. V., Ocean-atmosphere coupling over monsoon regions. Nature, 1984, 312, 141143.

18. Graham, N. E. and Barnett, T. P., Sea surface temperature, surface wind divergence, and convection over tropical oceans. Science, 1987, 238, 657-659.

19. Francis, P. A., Gadgil, Sulochana and Vinayachandran, P. N., Triggering of the positive Indian Ocean dipole events by severe cyclones over the Bay of Bengal. Tellus A, 2007, 59(4) 461-475; doi:10.1111/j.1600-0870.2007.00254.x

20. Vinayachandran, P. N., Iizuka, S. and Yamagata, T., Indian Ocean dipole mode events in an ocean general circulation model. Deep Sea Res. Part II, 2002, 49, 1573-1596.

ACKNOWLEDGEMENTS. We thank the reviewers for detailed and insightful comments which helped to improve the manuscript. This is INCOIS publication number 347. Financial support from O-MASCOT project of INCOIS is acknowledged.

Received 16 August 2019; accepted 20 August 2019

doi: $10.18520 / \mathrm{cs} / \mathrm{v} 117 / \mathrm{i} 5 / 783-793$ 